\title{
Risk factors for asthma and allergic diseases in school children across Lebanon
}

\author{
Mirna Waked' \\ Pascale Salameh ${ }^{2}$ \\ 'Balamand University, Beirut, Lebanon; \\ ${ }^{2}$ Lebanese University, Faculty of Public \\ Health, Section II, Fanar, Lebanon
}

\begin{abstract}
Introduction: Childhood asthma is one of important diseases of childhood. There is no known prevalence of asthma and allergic diseases in Lebanon. This study was conducted with a secondary objective of finding the odds of exposure to asthma, allergic rhinitis and eczema potential risk factors in Lebanese children.

Material and methods: It is a cross-sectional study on children in public and private schools. A sample of 22 schools participated, where standardized written core questionnaires were distributed. 5-12 year old students completed the questionnaires at home, while 13-14 year old students filled it in class.

Results: 5522 children were evaluated for asthma, allergic rhinitis and atopic eczema prevalence and their associated factors. These diseases seem to be similarly affected by parental respiratory problems, parental smoking, infancy gastroesophageal reflux, recurrent otitis, and previous pertussis. Humidity on the bedroom walls is associated with both asthma and allergic rhinitis, a spongy pillow with both allergic rhinitis and eczema, animal possession with asthma, and noncotton mattress with atopic eczema. The adjusted odds ratios for significant associations varied between 1.25 and $3(0.0001<$ p-value $<0.01)$.
\end{abstract}

Conclusion: These factors are preventable, thus permitting a possible reduction of the prevalence of these diseases.

Keywords: asthma, eczema, rhinitis, allergic disease, risk factors

\section{Introduction}

Childhood asthma is one of the most important diseases of childhood. ${ }^{1}$ Despite a decrease of mortality around the world, it is still taxed by high morbidity. ${ }^{2}$ The natural history of asthma is still largely unknown ${ }^{3}$ and risk factors for asthma and other allergic diseases such as rhinitis and eczema are currently studied and discussed, ${ }^{4-6}$ but remain controversial on many issues. ${ }^{3,7}$ Although genetic predisposition and environmental exposure are thought to lead to the development of these conditions, the nature of such associations remains unclear. ${ }^{7,8}$

We have recently conducted an epidemiological study in Lebanon, with the objective of determining prevalence and risk factors of allergic diseases in Lebanon schoolchildren. Prevalence data have been reported previously: allergic diseases were found to be on the medium prevalence trend noted all over the world. ${ }^{9,10}$ The present analysis was performed to determine which factors were independently associated with asthma, allergic rhinitis, atopic eczema, or any combination of these.

\section{Material and methods}

\section{Study design}

Our study is an analytical cross-sectional study carried out on school children in Lebanon.

The dependent variables were physician-diagnosed asthma, assessed by the answer to the question: "Has your doctor ever said you had asthma?" Asthma symptoms such 
as wheezing ever, last 12 months wheezing, and wheezing on exercise without physician diagnosis, according to the International Study of Asthma and Allergies in Childhood (ISAAC) questionnaire ${ }^{11}$ were also evaluated. A probable asthma was defined as physician diagnosed asthma or having suffered from any asthma symptoms (wheezing ever, 12 months wheezing, or wheezing on exercise).

Allergic rhinitis was also assessed by the question: "Have you ever had a problem with sneezing, or a runny or blocked nose when you did not have cold?" In addition, atopic eczema was considered positive if the individual answered yes to one of the following questions: "Have you ever had eczema?" Or "Have you ever had an itchy rash on the folds of the elbows, behind the knees, in front of the ankles, under the buttocks, or around the neck, ears or eyes?"

Any allergic disease was defined as having probable asthma, allergic rhinitis, or atopic eczema.

Independent variables were age, school type, sex, parental education, and potential risk factors of asthma and allergic diseases, such as parental smoking, parental respiratory problem, infancy gastro esophageal reflux, recurrent otitis, bedroom carpet presence, humidity in bedroom, animal possession, type of mattress and pillow, and heating manner, etc.

\section{Methods}

The sampling unit was a school. Thirty schools were randomly selected from a list of schools provided by the Ministry of Education: 13 public and 17 private schools. Eight schools ( 1 public and 7 private) refused to participate, while 22 out of $30(73.3 \%)$ agreed to distribute the questionnaires to their students between first and ninth grades. Standardized questionnaires were distributed to children aged 5 to 12 years and they had to take the questionnaire home to be completed by their parents and returned to school to be picked up by the inquirer, while others were distributed to children aged 13 to 14 years who would complete the questionnaire at school, supervised by the enquirer.

The standardized ISAAC written core questionnaire was used, after translation into Arabic and translation back into English to ensure questions accuracy. ${ }^{11,12}$ Additional details about the study methodology exist in specific publications. ${ }^{9,10}$

\section{Statistical analysis}

Questionnaires were coded and data introduced on Statistical Package for Social Sciences (SPSS) software (version 12.0; SPSS Inc., Chicago, IL, USA) by independent lay persons. Data entry was then controlled twice, and data analysis was performed by the same SPSS software. Weighting cases was performed according to population distribution by age group, sex and governate in Lebanon by Central Administration of Statistics. ${ }^{13}$ Cluster effect was taken into account according to the method suggested by Rumeau-Rouquette and collaborators. ${ }^{14}$

A p-value $<0.05$ was considered significant. The Chi-square test was used for comparison between categorical variables, while Student test was used for comparison of means between groups. For multivariate analysis, stepwise backward likelihood ratio logistic regressions were performed for diseases, taking into account the studied sociodemographic and factors that presented a significant or a borderline $(\mathrm{p}<0.20)$ association in bivariate analysis. Adjusted odds ratios $\left(\mathrm{OR}_{\mathrm{a}}\right)$ were then calculated.

\section{Results}

In Table 1, questionnaires distribution across Lebanese governate is presented. 7679 questionnaires were distributed, and overall response rate was $72 \%$. After weighting on distribution by age group, sex, and governate in Lebanon, analysis was finally done on 5544 questionnaires (Table 1).

Public schools $\left(\mathrm{OR}=1.67 ; \mathrm{p}<10^{-4}\right)$, higher age categories $\left(\mathrm{p}<10^{-4}\right)$, male sex $\left(\mathrm{OR}_{\mathrm{a}}=1.36 ; \mathrm{p}<10^{-4}\right)$, and father and mother lower education $\left(\mathrm{p}<10^{-4}\right)$ are associated with higher odds of probable asthma, defined as physician diagnosed asthma or asthma symptoms (all wheezing) (Table 2). A smoking mother $(\mathrm{OR}=1.43)$, a smoking father $(\mathrm{OR}=1.30)$, a father $(\mathrm{OR}=2.33)$, or mother lung problem $(\mathrm{OR}=2.22)$, infancy gastroesophageal reflux $(\mathrm{OR}=2.13)$, recurrent otitis $(\mathrm{OR}=2.38)$, heart problem $(\mathrm{OR}=4.60)$, previous pertussis $(\mathrm{OR}=3.39)$, humidity on bedroom walls $(\mathrm{OR}=1.79)$, and animal possession $(\mathrm{OR}=1.57)$ were all significantly associated with probable asthma (Table 3 ).

On the other hand, age and infant day care attendance $(\mathrm{OR}=1.23)$ were also found to be associated with allergic rhinitis (Table 2). A father $(\mathrm{OR}=2.33)$, or mother lung problem $(\mathrm{OR}=2.22)$, a smoking father $(\mathrm{OR}=1.32)$ or mother $(\mathrm{OR}=1.20)$, infannt gastroesophageal reflux disease $\left(\mathrm{OR}_{\mathrm{a}}=2.11\right)$, recurrent otitis $(\mathrm{OR}=2.27)$, previous pertussis $(\mathrm{OR}=1.23)$, humidity on bedroom walls $(\mathrm{OR}=1.56)$, and a spongy pillow $(\mathrm{OR}=1.39)$ were also significantly associated with allergic rhinitis (Table 3 ).

For atopic eczema, no association was found for any socioeconomic factor, except for a protective effect for the child when sleeping in his own bed $(\mathrm{OR}=0.73 ; \mathrm{p}=0.001)$ (Table 2). However a father $(\mathrm{OR}=1.72)$, or mother $(\mathrm{OR}=2.27)$ lung problem, recurrent otitis $(\mathrm{OR}=2.17)$, 
Table I Questionnaires distribution by governate

\begin{tabular}{|c|c|c|c|c|}
\hline Governate & Total distributed & Total questionnaires ${ }^{a}$ & Weight $^{b}$ & $\begin{array}{l}\text { Weighted numbers } \\
\text { and percentages }\end{array}$ \\
\hline Bekaa & 1370 & $784(14.2 \%)$ & 0.89 & $698(12.6 \%)$ \\
\hline Beirut & 388 & $324(5.9 \%)$ & 1.76 & $570(10.3 \%)$ \\
\hline Mount Lebanon & 2572 & 2225 (40.3\%) & 0.99 & 2203 (39.7\%) \\
\hline El Nabatieh & 935 & $653(11.8 \%)$ & 0.50 & 327 (5.9\%) \\
\hline North Lebanon & $|83|$ & 1244 (22.5\%) & 0.91 & II 57 (20.9\%) \\
\hline South Lebanon & 583 & $292(5.3 \%)$ & 2.02 & $590(10.6 \%)$ \\
\hline Total & 7679 & $5522(100 \%)$ & & $5544(100 \%)^{c}$ \\
\hline
\end{tabular}

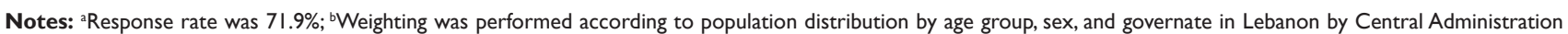
of Statistics. ${ }^{13}$

previous pertussis $(\mathrm{OR}=1.28)$, a spongy pillow $(\mathrm{OR}=1.61)$, an artificial $(\mathrm{OR}=1.25)$ mattress were significantly associated with atopic eczema (Table 3 ).

When these allergic diseases were combined together, risk factors identified as significantly associated with their occurrence were nearly identical to those of individual diseases (Tables 2 and 3 ).

All the results of bivariate analysis were confirmed by multivariate analysis in the majority of cases, while some risk factors lost the significant association found in bivariate analysis (Table 4).

\section{Discussion}

This is a cross sectional study carried on schoolchildren in Lebanon, addressing potential risk factors for asthma, rhinitis and eczema. Male sex was found a significant risk factor for asthma. It has been shown previously in the literature that male sex is predominant in asthma population in the first decade. ${ }^{15}$ Indeed our sample included school children from 5-14-years-old and few of them were in the category of 13-14-years-old. On the other hand, older age was also found a risk factor for asthma in our study. This seems logical considering the cumulative years' effect in asthma which is a chronic disease. ${ }^{3}$ Again, being in public schools was retained in our model as a risk factor for asthma, and children going to public schools were found - in previous personal publications $^{16}$ - less controlled for their disease. According to data in the literature where a less favorable environment per se is observed as impacting asthma; ${ }^{17}$ we might argue that being in public schools in Lebanon may reflect indirectly a low socioeconomic status.

Familial history for lung diseases in the mother and the father is also a risk factor for asthma retained in our model. This has been shown in previous studies specifically for familial history of atopy. ${ }^{3,8}$ On the other hand, the effect of smoking parents on children has been shown to be a triggering factor to express asthma in children even in early life. ${ }^{8,18,19}$ In our models, both the smoking mother and father were shown to be risk factor for asthma and allergic diseases. The parents' education was not shown to be risk factor for asthma and allergic diseases in multivariate analysis, although we found in previous analyses that the low mother education was correlated to a worse control of asthma. ${ }^{16}$

Environmental factors found associated with asthma in our population were the presence of molds on bedrooms' walls and pets' possession. This is also in concordance with other studies. ${ }^{3,7,20}$ Although dust mites are known indoor environmental factor for asthma, ${ }^{3,7,20}$ they were not found in our study as so. Indeed, the floor coverage with carpets in the bedroom or the use of feather pillows ${ }^{7,20,21}$ reflects indirectly the hypothetical presence or absence of dust mites. In our questionnaires, the questions addressing the house environment were subdivided into numerous items that might not precisely reflect the dust mites' presence. Another possible reason is that our study is an epidemiologic one, and was not designed to document atopy by skin prick tests as per example.

Recurrent otitis is a risk factor for asthma and allergic diseases in our study. The known risk factors for recurrent ear infections include atopy, male gender, and day care attendance, ${ }^{22}$ while few studies have showed a positive strong association between asthma and recurrent ear infections per se among children. ${ }^{23}$ This relationship needs further prospective studies to be closely depicted. In addition, heart problems were found correlated to higher risk of asthma in this study. Interestingly a recent prospective study by Massin and collaborators ${ }^{24}$ showed that a substantial proportion of children with congenital heart disease have significant non cardiac co morbidities, among which asthma was found the most frequent. Moreover, pertussis infection is found to be a 
Table 2 Socioeconomic factors associated with allergic diseases

\begin{tabular}{|c|c|c|c|c|c|}
\hline $\begin{array}{l}\text { Disease status/ } \\
\text { Socioeconomic } \\
\text { factors }\end{array}$ & $\begin{array}{l}\text { Total exposure } \\
N=5544(100 \%)\end{array}$ & $\begin{array}{l}\text { Probable asthma }^{a} \\
N=1082(19.5 \%)\end{array}$ & $\begin{array}{l}\text { Allergic rhinitis } \\
N=1360(24.5 \%)\end{array}$ & $\begin{array}{l}\text { Atopic eczema } \\
N=64 \mid(11.6 \%)\end{array}$ & $\begin{array}{l}\text { Any allergic disease } \\
N=2196(39.6 \%)\end{array}$ \\
\hline Public school vs & $|78|$ (32.|\%) & $<10^{-4} ; 1.67$ & $0.10 ; 1.11$ & $0.29 ; 1.10$ & $<10^{-4} ; 1.38$ \\
\hline Private school & 3763 (67.9\%) & [1.45-1.92] & [0.98-1.27] & {$[0.93-1.30]$} & [1.23-1.55] \\
\hline \multicolumn{6}{|l|}{ Age category } \\
\hline [5-8] years & I 585 (28.6\%) & $1.00 ;<10^{-4}$ & $1.00 ;<10^{-4}$ & $1.00 ; 0.98$ & $1.00 ;<10^{-4}$ \\
\hline$[8-10]$ years & 1202 (21.7\%) & $1.03[0.84-1.26]$ & $1.15[0.96-1.39]$ & $1.03[0.82-1.31]$ & $1.07[0.91-1.25]$ \\
\hline$[10-13]$ years & 1796 (32.4\%) & $1.48[1.25-1.78]$ & $1.37[1.16-1.61]$ & $1.00[0.81-1.24]$ & $1.36[1.18-1.56]$ \\
\hline$>13$ years & 960 (17.3\%) & $2.06[\mid .70-2.5 I]$ & $2.22[1.85-2.66]$ & $0.98[0.76-1.26]$ & $2.00[1.70-2.36]$ \\
\hline Male sex & $2890(52.2 \%)$ & $\begin{array}{l}<10^{-4} ; 1.39 \\
{[1.20-1.59]}\end{array}$ & $\begin{array}{l}0.37 ; 1.05 \\
{[0.93-1.19]}\end{array}$ & $\begin{array}{l}0.44 ; 1.06 \\
{[0.90-1.27]}\end{array}$ & $\begin{array}{l}0.001 ; 1.19 \\
{[1.07 ; 1.33]}\end{array}$ \\
\hline \multicolumn{6}{|l|}{ Father education } \\
\hline Low & 1259 (23.4\%) & $1.43[1.19-1.72]$ & I.I 5 [0.97-I.37] & $1.15[0.91-1.45]$ & $1.28[1.10 ; 1.49]$ \\
\hline Intermediate & 25 I8 (46.7\%) & $1.09[0.92-1.28]$ & $1.04[0.91-1.22]$ & $1.02[0.83-1.25]$ & $1.08[0.95 ; 1.22]$ \\
\hline High & 1613 (29.9\%) & $1.00 ;<10^{-4}$ & $1.00 ; 0.17$ & $1.00 ; 0.44$ & $1.00 ; 0.004$ \\
\hline \multicolumn{6}{|l|}{ Mother education } \\
\hline Low & $963(17.8 \%)$ & $1.39[1.15-1.67]$ & $\mathrm{I} .14[0.94-1.37]$ & $1.09[0.85-1.39]$ & 1.21 [1.04; I.42] \\
\hline Intermediate & $2659(49.3 \%)$ & $\mathrm{I} .02[0.87-1.20]$ & $1.03[0.91-1.19]$ & $0.88[0.73-1.08]$ & $1.02[0.96 ; 1.06]$ \\
\hline High & I 775 (32.9\%) & $1.00 ;<10^{-4}$ & $1.00 ; 0.39$ & $1.00 ; 0.17$ & $1.00 ; 0.038$ \\
\hline $\begin{array}{l}\text { Child sleeps in his } \\
\text { own bed }\end{array}$ & 4824 (87.9\%) & $\begin{array}{l}0.02 ; 0.79 \\
{[0.65-0.96]}\end{array}$ & $\begin{array}{l}0.03 ; 0.82 \\
{[0.69-0.99]}\end{array}$ & $\begin{array}{l}0.01 ; 0.73 \\
{[0.58-0.92]}\end{array}$ & $\begin{array}{l}0.01 ; 0.81 \\
{[0.69-0.95]}\end{array}$ \\
\hline Infancy daycare & I 30 (23.8\%) & $\begin{array}{l}0.32 ; 0.92 \\
{[0.79-1.08]}\end{array}$ & $\begin{array}{l}0.003 ; 1.23 \\
{[1.08-1.43]}\end{array}$ & $\begin{array}{l}0.29 ; 1.11 \\
{[0.92-1.33]}\end{array}$ & $\begin{array}{l}0.02 ; 1.22 \\
{[1.07 ; 1.38]}\end{array}$ \\
\hline Electrical vacuum & 4917 (89.4\%) & $\begin{array}{l}0.39 ; 0.91 \\
{[0.74-1.13]}\end{array}$ & $\begin{array}{l}0.10 ; 1.19 \\
{[0.97-1.46]}\end{array}$ & $\begin{array}{l}0.60 ; 1.08 \\
{[0.82-1.42]}\end{array}$ & $\begin{array}{l}0.97 ; 1.00 \\
{[0.84 ; 1.19]}\end{array}$ \\
\hline \multicolumn{6}{|l|}{$\begin{array}{l}\text { Persons per } \\
\text { chamber }\end{array}$} \\
\hline$>1.6$ & 1826 (32.9\%) & $0.99[0.83-1.19]$ & $1.12[0.95-1.33]$ & $0.90[0.72-1.13]$ & $1.08[0.93-1.25]$ \\
\hline $1-1.6$ & $2493(45.0 \%)$ & $1.03[0.87-1.22]$ & $1.12[0.96-1.32]$ & 1.11 [0.90-1.38] & $1.12[0.98-1.30]$ \\
\hline$<1$ & 1225 (22.1\%) & $0.92 ; 1.00$ & $0.17 ; 1.00$ & $0.37 ; 1.00$ & $0.30 ; 1.00$ \\
\hline
\end{tabular}

Note: aProbable asthma includes asthma-like symptoms with or without physician diagnosis.

risk factor for asthma in our study. This has been a debatable issue and controversial matter. This controversy is related mainly to the "hygiene hypothesis" 25,26 where is debated the protective ${ }^{21}$ or nonprotective effect ${ }^{20}$ of early endotoxin exposure-whether environmental or infectious - on developing atopic diseases. Some experimental studies and epidemiologic ones seem to confirm the non protective effect of previous Bordetella pertussis infection on bronchial hyper reactivity. ${ }^{27,28}$

Infant gastroesophageal reflux was also found a risk factor in our population. It has been reported that gastroesophageal reflux disease (GERD) occurs in about two thirds of children with asthma. ${ }^{29,30}$ It may simply represent a concomitant unrelated finding or it may be responsible for provoking or worsening asthma. ${ }^{30}$ GERD could also be a byproduct of asthma itself. In any case, aggressive treatment of GERD seems to improve asthma outcomes. GERD should be suspected in asthma patients who do not have any known risk factors or those who are becoming difficult to treat. ${ }^{29}$

As for asthma, some of the risk factors were found for allergic rhinitis too, in accordance with other studies: age, ${ }^{3,4}$ a parental lung problem, ${ }^{3-5}$ infant gastroesophageal reflux disease, ${ }^{29}$ recurrent otitis; ${ }^{22}$ previous pertussis,,${ }^{27,28}$ humidity on bedroom walls..$^{3-5}$ This is definitely a reflection of the same airway disease concept. ${ }^{4,8}$ A smoking father was found as a risk factor for rhinitis in our population. This is 
Table 3 Distribution of other risk factors for allergic diseases

\begin{tabular}{|c|c|c|c|c|c|}
\hline $\begin{array}{l}\text { Disease status/ } \\
\text { Factors }\end{array}$ & $\begin{array}{l}\text { Total } \\
N=5544(100 \%)\end{array}$ & $\begin{array}{l}\text { Probable asthma }^{a} \\
N=1082(19.5 \%)\end{array}$ & $\begin{array}{l}\text { Allergic rhinitis } \\
N=1360(24.5 \%)\end{array}$ & $\begin{array}{l}\text { Atopic eczema } \\
\mathrm{N}=640(1 \mathrm{I} .5 \%)\end{array}$ & $\begin{array}{l}\text { Any disease } \\
N=2196(39.6 \%)\end{array}$ \\
\hline Father lung disease & $40 \mathrm{I}(7.2 \%)$ & $<10^{-4} ; 2.33[1.89-2.86]$ & $<10^{-4} ; 2.22[1.79-2.70]$ & $<10^{-4} ; 1.72$ [1.32-2.27] & $<10^{-4} ; 2.35[1.91-2.89]$ \\
\hline Mother lung disease & $363(6.7 \%)$ & $<10^{-4} ; 2.22[1.75-2.78]$ & $<10^{-4} ; 2.13[1.69-2.63]$ & $<10^{-4} ; 2.27[1.75-2.94]$ & $<10^{-4} ; 2.64[2.12-2.29]$ \\
\hline Smoking mother & 1899 (35.1\%) & $<10^{-4} ; 1.43[1.23-1.64]$ & $0.004 ; 1.20$ [1.06-1.37] & $0.13 ; 1.14$ [0.96-1.35] & $<10^{-4} ; 1.28[1.14-1.49]$ \\
\hline Smoking father & $2848(53.0 \%)$ & $<10^{-4} ; 1.30[1.14-1.50]$ & $<10^{-4} ; 1.32[1.16-1.49]$ & $0.34 ; 1.09[0.92-1.28]$ & $<10^{-4} ; 1.29[1.15-1.44]$ \\
\hline $\begin{array}{l}\text { Infant gastroesopha- } \\
\text { geal reflux }\end{array}$ & $588(10.9 \%)$ & $<10^{-4} ; 2.13[1.75-2.56]$ & $0.36 ; 0.93[0.79-1.09]$ & $0.60 ; 0.94[1.16-0.77]$ & $<10^{-4} ; 2.65[2.22-3.16]$ \\
\hline Recurrent otitis & $1196(21.9 \%)$ & $<10^{-4} ; 2.38[2.08-2.78]$ & $<10^{-4} ; 2.27[1.89-2.70]$ & $<10^{-4} ; 2.17[1.72-2.70]$ & $<10^{-4} ; 2.42[2.12-2.75]$ \\
\hline Amygdalectomy & $308(5.6 \%)$ & $<10^{-4} ; 1.90[1.47-2.44]$ & $<10^{-4} ; 2.00[1.75-2.33]$ & $<10^{-4} ; 2.38[2.00-2.86]$ & $<10^{-4} ; 1.88[1.49-2.36]$ \\
\hline Heart problem & $85(1.6 \%)$ & $<10^{-4} ; 4.60$ [2.99-7.07] & $<10^{-4} ; 1.77$ [1.39-2.25] & $0.24 ; \mid .22[0.87-|.7|]$ & $<10^{-4} ; 3.17[2.01-5.00]$ \\
\hline Measles & $1240(23.4 \%)$ & $0.16 ; 1.12[0.96-1.31]$ & $<10^{-4} ; 2.40[1.56-3.70]$ & $0.002 ; 2.25[1.34-3.77]$ & $0.007 ; 1.19[1.05-1.36]$ \\
\hline Pertussis & 209 (3.9\%) & $<10^{-4} ; 3.39[2.56-4.50]$ & $0.005 ; 1.23$ [1.06-1.42] & $0.01 ; 1.28[1.06-1.55]$ & $<10^{-4} ; 3.22[2.41-4.32]$ \\
\hline Breastfeeding & $4472(81.3 \%)$ & $0.78 ; 1.02[0.86-1.22]$ & $<10^{-4} ; 2.51[1.90-3.33]$ & $<10^{-4} ; 2.28[1.62-3.20]$ & $0.51 ; 0.98[0.83-1.10]$ \\
\hline Moquette in Bedroom & $1778(32.4 \%)$ & $<10^{-4} ; 1.33[1.54-1.16]$ & $0.001 ; 1.25$ [1.10-1.43] & $0.02 ; 1.22[1.03-1.45]$ & $<10^{-4} ; 1.34[1.20-1.51]$ \\
\hline $\begin{array}{l}\text { Humidity on bedroom } \\
\text { walls }\end{array}$ & 921 (16.8\%) & $<10^{-4} ; 1.79[1,52-2.08]$ & $<10^{-4} ; 1.56[1.35-1.82]$ & $<10^{-4} ; 1.54$ [1.27-1.89] & $<10^{-4} ; 1.81$ [2.09-1.57] \\
\hline Animal possession & $1046(18.9 \%)$ & $<10^{-4} ; 1.57[1.34-1.84]$ & $0.005 ; 1.24$ [1.07-1.45] & $0.02 ; 1.27[1.04-1.55]$ & $<10^{-4} ; 1.43[1.25-1.64]$ \\
\hline Spongy pillow & 619 (11.4\%) & $0.08 ; 1.20$ [0.98-1.47] & $<10^{-4} ; 1.39$ [1.16-1.67] & $<10^{-4} ; 1.61$ [1.28-2.04] & $<10^{-4} ; 1.45[1.7 \mid-1.22]$ \\
\hline Feather pilow & $536(9.9 \%)$ & $0.34 ; 0.89[0.7 \mid-1.12]$ & $0.35 ; 1.10$ [0.90-1.35] & $0.68 ; 0.94[0.7 \mid-1.25]$ & $0.54 ; 0.97[0.86-1.08]$ \\
\hline Cotton pilow & $3720(68.4 \%)$ & $0.25 ; 0.92[0.79-1.06]$ & $0.03 ; 0.86[0.76-0.98]$ & $0.001 ; 0.75[0.63-1.14]$ & $0.009 ; 0.86[0.76-0.96]$ \\
\hline Wool mattress & $74 \mid(13.8 \%)$ & $0.27 ; 0.89[0.73-1.09]$ & $0.43 ; 1.08[0.90-1.28]$ & $0.10 ; 1.22[0.96-1.52]$ & $0.44 ; 1.04[0.95-1.14]$ \\
\hline Cotton mattress & I 367 (25.4\%) & $0.63 ; 1.04[0.89-1.22]$ & $0.45 ; 0.94[0.82-1.09]$ & $0.001 ; 0.69[0.56-0.85]$ & $0.09 ; 0.94[0.87-1.01]$ \\
\hline Artificial mattress & $3274(60.8 \%)$ & $0.65 ; 0.97[0.84-1.1 \mathrm{I}]$ & $0.68 ; 1.03[0.90-1.16]$ & $0.01 ; 1.25$ [1.05-1.49] & $0.5 \mathrm{I} ; 1.02[0.96-1.10]$ \\
\hline Butane heating & 1607 (29.3\%) & $0.35 ; 0.93[0.80-1.07]$ & $0.9 \mid ; 1.01$ [0.88-I.I5] & $0.01 ; 0.79[0.65-0.95]$ & $0.91 ; 0.90[0.80-1.02]$ \\
\hline Diesel heating & 1292 (23.6\%) & $0.04 ; 0.85[0.7 \mid-0.99]$ & $0.04 ; 1.16[1.01-1.33]$ & $0.18 ; 1.14$ [0.94-1.37] & $0.66 ; 0.97[0.86-1.05]$ \\
\hline Wood heating & $864(8.5 \%)$ & $0.56 ; 1.08$ [0.85-1.35] & $0.24 ; 0.88[0.69-1.10]$ & $0.53 ; 1.10$ [0.82-1.47] & $0.55 ; 1.06[0.87-1.29]$ \\
\hline Coal heating & $154(2.8 \%)$ & $0.04 ; 1.47[1.02-2.13]$ & $1.00 ; 1.00[0.69-1.45]$ & $0.27 ; 1.30[0.82-2.04]$ & $0.04 ; 1.40[1.02-1.93]$ \\
\hline
\end{tabular}

Note: aProbable asthma includes asthma-like symptoms with or without physician diagnosis.

consistent with results of the literature where environmental tobacco smoke was found a risk factor for rhinitis. ${ }^{5}$ On the other hand, the use of a spongy pillow was also significantly associated with an increased risk of allergic rhinitis in our population which also is consistent with literature findings..$^{3-5}$ Interestingly enough, infant day care attendance was found associated with allergic rhinitis in our study. In previous studies, no sign of protection from day care attendance for allergic diseases was found up to 6 years of age, ${ }^{31}$ and multiple airway infections and day care attendance were found to be independently associated with asthma and allergic symptoms. ${ }^{31}$

For atopic eczema, no association was found for any socioeconomic factor in our population, except for the child sleeping in his own bed. However a father or mother lung problem, ${ }^{6}$ the use of a spongy pillow, wool or an artificial mattress were shown significantly associated with atopic eczema, ${ }^{7}$ both in the literature and in our study. Infant GERD, recurrent otitis, previous pertussis were also risk factors for eczema in our population. This may be explained by what has been reported in the literature, where eczema, asthma and allergic rhinitis are parts of the same atopic disease. ${ }^{3,6}$

We are aware of the possible biases introduced by this study design. A selection bias is possible because of the refusal of the 8 schools to participate to the study, 7 of them being private. We would expect this to have caused the underestimation of diagnosed asthma but the overestimation of undiagnosed diseases and symptoms in our study. An information bias is also possible since the use of a questionnaire in a young population or for surrogate responders (parents) may not always be accurate: problems in question understanding, recall deficiency and over or under evaluating symptoms may still be possible. 
Table 4 Multivariate analysis of allergic diseases ${ }^{a}$

\begin{tabular}{|c|c|c|c|c|}
\hline $\begin{array}{l}\text { Factors } \\
\text { in the model }\end{array}$ & $\begin{array}{l}\text { Probable asthma } \\
N=1082(19.5 \%)\end{array}$ & $\begin{array}{l}\text { Allergic rhinitis } \\
N=1360(24.5 \%)\end{array}$ & $\begin{array}{l}\text { Atopic eczema } \\
N=640(11.5 \%)\end{array}$ & $\begin{array}{l}\text { Any disease } \\
N=2196(39.6 \%)\end{array}$ \\
\hline Age category & $<10^{-4}$ & $<10^{-4}$ & Not retained in the model & $<10^{-4}$ \\
\hline$\leq$ 8years & $<10^{-4} ; 0.48[0.40-0.59]$ & $<10^{-4} ; 0.41[0.33-0.51]$ & & $<10^{-4} ; 0.58[0.46-0.74]$ \\
\hline$[8-10]$ years & $<10^{-4} ; 0.49[0.40-0.60]$ & $<10^{-4} ; 0.45[0.37-0.56]$ & & $<10^{-4} ; 0.51[0.40-0.66]$ \\
\hline$[10-13]$ years & $<10^{-4} ; 0.63[0.52-0.76]$ & $<10^{-4} ; 0.58[0.47-0.70]$ & & $0.005 ; 0.73[0.59-0.91]$ \\
\hline$>13$ years & 1.00 & 1.00 & & 1.00 \\
\hline Male sex & $0.002 ; 1.22[1.05-1.40]$ & Not retained in the model & Not retained in the model & $<10^{-4} ; 1.34[1.15-1.57]$ \\
\hline Pertussis & $<10^{-4} ; 2.32[1.66-3.25]$ & $<10^{-4} ; 1.91$ [1.38-2.63] & $0.01 ; 1.65$ [1.12-2.44] & $<10^{-4} ; 2.85[2.06-3.96]$ \\
\hline Animal possession & $0.005 ; \mid .26[1.07-\mid .47]$ & Not retained in the model & Not retained in the model & $0.005 ; 1.31$ [1.08-I.57] \\
\hline Mother lung disease & $<10^{-4} ; 1.98[1.55-2.53]$ & $<10^{-4} ; 1.72$ [1.34-2.20] & $<10^{-4} ; 2.11[1.58-2.81]$ & $<10^{-4} ; 1.64[1.25-2.13]$ \\
\hline Father lung disease & $<10^{-4} ; 2.04[1.63-2.57]$ & $<10^{-4} ; 1.89[1.50-2.39]$ & $0.02 ; 1.43[1.06-1.93]$ & $<10^{-4} ; 2.05[1.60-2.62]$ \\
\hline Smoking father & $0.003 ; 1.21$ [1.07-1.37] & $0.004 ; 1.23[1.07-1.41]$ & Not retained in the model & Not retained in the model \\
\hline Smoking mother & Not retained in the model & Not retained in the model & Not retained in the model & $0.002 ; 1.29$ [1.1I0-1.52] \\
\hline $\begin{array}{l}\text { Infant gastroesophageal } \\
\text { reflux }\end{array}$ & $<10^{-4} ; 2.28[1.88-2.78]$ & $<10^{-4} ; 2.11$ [1.73-2.57] & $<10^{-4} ; 1.72[1.35-2.20]$ & $<10^{-4} ; 1.71$ [1.38-2.13] \\
\hline Cotton mattress & $0.04 ; 0.86[0.74-0.99]$ & Not retained in the model & $0.003 ; 0.70[0.56-0.88]$ & Not retained in the model \\
\hline Spongy pillow & $0.003 ; 1.33[1.10-1.61]$ & $0.008 ; 1.32[1.07-1.61]$ & $0.003 ; 1.46[1.14-1.88]$ & Not retained in the model \\
\hline $\begin{array}{l}\text { Humidity on } \\
\text { bedroom walls }\end{array}$ & $<10^{-4} ; 1.51$ [1.29-1.77] & $<10^{-4} ; 1.40$ [I.18-I.66] & $0.05 ; 1.25[1.00-1.56]$ & $<10^{-4} ; 1.46[1.21-1.76]$ \\
\hline Moquette in bedroom & $0.02 ; 1.18$ [1.03-1.34] & Not retained in the model & Not retained in the model & $0.09 ; 1.15[0.98-1.35]$ \\
\hline Amygdalectomy & $0.03 ; 1.35[1.03-1.76]$ & $0.06 ; 1.30[0.98-1.71]$ & Not retained in the model & $0.06 ; 1.32$ [0.98-1.77] \\
\hline Recurrent otitis & $<10^{-4} ; 2.23[1.92-2.58]$ & $<10^{-4} ; 1.82[1.56-2.14]$ & $<10^{-4} ; 2.04[1.68-2.48]$ & $<10^{-4} ; 2.27[1.92-2.68]$ \\
\hline Infancy daycare & $0.01 ; 1.22[1.05-1.40]$ & $0.005 ; 1.25[1.07-1.47]$ & Not retained in the model & Not retained in the model \\
\hline Public school & Not retained in the model & Not retained in the model & Not retained in the model & $0.003 ; 1.28[1.09-1.52]$ \\
\hline
\end{tabular}

Notes: ather factors not retained in the final logistic regression model include: father and mother education, child sleeps in his own bed, electrical vacuum possession, number of persons per chamber, heart problem, measles, breastfeeding, feather pillow, cotton pillow, wool mattress, artificial mattress, butane heating, diesel heating, wood heating, coal heating; ${ }^{b}$ Probable asthma includes asthma-like symptoms with or without physician diagnosis.

The same applies for different potential risk factors. In addition, some questions may refer to potential risk factors that do not necessarily precede the disease, suggestive of the temporality problem found in cross-sectional designs. However, our methodology is that of other cross-sectional studies, including ISAAC ones, which is necessary for international comparisons. As for causality assessment between potential risk factors and allergic diseases, it is beyond the scope of our work. Nevertheless, several previous reviews have carefully evaluated the matter and proved causality with more or less strong evidence between much of the associated factors we found and allergic diseases. ${ }^{7,32}$

\section{Conclusion}

Asthma, allergic rhinitis and eczema seem to be similarly affected by several risk factors in our population of Lebanese school children across Lebanon. The majority of these factors are preventable, thus permitting a possible reduction of the prevalence of these allergic diseases.

\section{Disclosure}

The authors report no conflicts of interest in this work.

\section{References}

1. The International Study of Asthma and Allergies in Childhood (ISAAC) Steering Committee. Worldwide variation in prevalence of symptoms of asthma, allergic rhino conjunctivitis, and atopic eczema: ISAAC. Lancet. 1998;351:1225-32.

2. van Schayck CP, Smit HA. The prevalence of asthma in children: a reversing trend. Eur Respir J. 2005;26:647-50.

3. Porsbjerg C, Von Linstow ML, Ulrik CS, Nepper-Christensen C, Backer V. Risk factors for onset of asthma: a 12 year prospective follow up study. Chest. 2006;129:309-16.

4. Koh YY, Kim CK. The development of asthma in patients with allergic rhinitis. Curr Opin Allergy Clin Immunol. 2003;3:159-64.

5. Biagini JM, Le Masters GK, Levin L, et al. Environmental risk factors of rhinitis in early infancy. Pediat Allergy Immunol. 2006; 17:278-84.

6. Kurukulaaratchy R, Matthews M, Arshad SH. The prevalence, characteristics of an early life risk factors for eczema in 10 year old children. Pediatr Allergy Immunol. 2003;14:178-83. 
7. Richardson G, Eick S, Jones R. How is indoor environment related to asthma? Literature review. J Adv Nurs. 2005;52:328-39.

8. Postma DS, Boezen MH. Allergy and airway hyperresponsiveness as genetic factors and their interaction with environment in the development of asthma and COPD. Chest. 2004;126:96S-104S.

9. Waked M, Salameh P. Asthma, allergic rhinitis and eczema in 13-14year-old school children across Lebanon. J Med Liban. 2006; 54:181-90.

10. Waked M, Salameh P. Prevalence of asthma, allergic rhinitis and eczema in 5-12-year-old school children across Lebanon. Public Health. 2008; 122:965-73.

11. Asher MI, Keil U, Anderson HR, et al. International study of asthma and allergies in childhood (ISAAC): rationale and methods. Eur Respir J. 1995;8:483-91.

12. Lewis TC, Stout JW, Martinez P, et al. Prevalence of asthma and chronic respiratory symptoms among Alaska native children. Chest. 2004; 125:1665-73.

13. Central Administration of Statistics. The National Study for Households Living Conditions in 2004, Beirut. [2005 Jul 7; cited 2006 Aug 1] Available from http://www.cas.org.

14. Rumeau-Roquette C, Breart G, Padieu R. Méthodes en Epidémiologie: Echantillonnage, investigations, analyse. Paris: Flammarion edition; 1985; p. 71-82.

15. Yeats K, Davis KJ, Sotir M, Herget C, Shy C. Who gets diagnosed with asthma? Frequent wheeze among adolescents with and without a diagnosis of asthma. Pediatrics. 2003;111:1046-54.

16. Waked M, Salameh P. Symptoms, severity and asthma control in 5-14year-old Lebanon school children. J Med Liban. 2007;55:145-51.

17. Corvalan C, Amigo H, Bustos P, Rona R. Socioeconomic risk factor for asthma in Chilean young adults. $J$ Public Health. 2005;95:1375-81.

18. Li YF, Langholz B, Salam MT, Frank GD. Maternal and grand maternal smoking patterns are associated with early childhood asthma. Chest. 2005;127:1232-41.

19. Arshad SH, Kurukulaaratchy RJ, Fenn M, Matthews S. Early life risk factors for current wheeze, asthma, and bronchial hyperresponsiveness at 10 years of age. Chest. 2005;127:502-8.

20. Te Pas CE, Litonjua AA, Celedon JC, Sredl D, Gold DR. Sensitization to aeroallergens and airway hyperresponsiveness at 7 years of age. Chest. 2006;129:1500-8.
21. Schram-Bijkerk D, Doekes G, Boeve M, et al; the PARSIFAL study group. Nonlinear relations between house dust mite allergen levels and mite sensitization in farm and non farm children. Allergy. 2006; 61:640-7.

22. Eldeirawi K, Persky VW. History of ear infections and prevalence of asthma in a national sample of children aged 2 to 11 years: the Third National Health and Nutrition Examination Survey, 1988 to 1994. Chest. 2004;125:1685-92.

23. Lieu JE, Feinstein AR. Effect of gestational and passive smoke exposure on ear infections in children. Arch Pediatr Adolesc Med. 2002; 156:147-54.

24. Massin MM, Astadicko I, Dessy H. Noncardiac comorbidities of congenital heart disease in children. Acta Paediatr. 2007;96:753-5.

25. Braun-Fahrländer C, Riedler J, Herz U, et al; the Allergy and Endotoxin Study Team. Environmental exposure to endotoxin and its relation to asthma in school-age children. N Engl J Med. 2002;347:869-77.

26. Tavernier G, Fletcher G, Gee I, et al. IPEADAM study: Indoor endotoxin exposure, family status, and some housing characteristics in English children. J Allergy Clin Immunol. 2006;117:656-62.

27. Ennis DP, Cassidy JP, Mahon BP. Prior Bordetella pertussis infection modulates allergen priming and the severity of airway pathology in a murine model of allergic asthma. Clin Exp Allergy. 2004;34:1488-97.

28. Dong W, Selgrade MK, Gilmour MI. Systemic administration of Bordetella pertussis enhances pulmonary sensitization to house dust mite in juvenile rats. Toxicol Sci. 2003;72:113-21.

29. Debley JS, Carter ER, Redding GJ. Prevalence and impact of gastroesophageal reflux in adolescents with asthma: a population-based study. Pediatr Pulmonol. 2006;41:475-81.

30. Leggett JJ, Johnston BT, Mills M, Gamble J, Heaney LG. Prevalence of gastroesophageal reflux in difficult asthma: relationship to asthma outcome. Chest. 2005;127:1227-31.

31. Hagerhed-Engman L, Bornehag CG, Sundell J, Aberg N. Day-care attendance and increased risk for respiratory and allergic symptoms in preschool age. Allergy. 2006;61:447-53.

32. Institute for Environment and Health (IEH). Indoor air quality in the home: Final report on DETR contract EPG 1/5/12 (Web Report W7) [cited Aug 18, 2005].Leicester, UK: IEH. Available from http://www. le.ac.uk/ieh/pdf/w7.pdf. 
